\title{
Controls on the temporal and spatial variability of soil moisture in a mountainous landscape: the signature of snow and complex terrain
}

\author{
C. J. Williams ${ }^{1}$, J. P. McNamara ${ }^{2}$, and D. G. Chandler ${ }^{3}$ \\ ${ }^{1}$ Northwest Watershed Research Center, USDA - Agricultural Research Service, Boise, ID, USA \\ ${ }^{2}$ Department of Geosciences, Boise State University, Boise, ID, USA \\ ${ }^{3}$ Department of Civil Engineering, Kansas State University, Manhattan, KS, USA
}

Received: 30 January 2008 - Published in Hydrol. Earth Syst. Sci. Discuss.: 17 July 2008

Revised: 29 January 2009 - Accepted: 9 July 2009 - Published: 28 July 2009

\begin{abstract}
The controls on the spatial distribution of soil moisture include static and dynamic variables. The superposition of static and dynamic controls can lead to different soil moisture patterns for a given catchment during wetting, draining, and drying periods. These relationships can be further complicated in snow-dominated mountain regions where soil water input by precipitation is largely dictated by the spatial variability of snow accumulation and melt. In this study, we assess controls on spatial and temporal soil moisture variability in a small $\left(0.02 \mathrm{~km}^{2}\right)$, snow-dominated, semi-arid catchment by evaluating spatial correlations between soil moisture and site characteristics through different hydrologic seasons. We assess the relative importance of snow with respect to other catchment properties on the spatial variability of soil moisture and track the temporal persistence of those controls. Spatial distribution of snow, distance from divide, soil texture, and soil depth exerted significant control on the spatial variability of moisture content throughout most of the hydrologic year. These relationships were strongest during the wettest period and degraded during the dry period. As the catchment cycled through wet and dry periods, the relative spatial variability of soil moisture tended to remain unchanged. We suggest that the static properties in complex terrain (slope, aspect, soils) impose first order controls on the spatial variability of snow and resulting soil moisture patterns, and that the interaction of dynamic (timing of water input) and static influences propagate that relative constant spatial variability through most of the hydrologic year. The
\end{abstract}

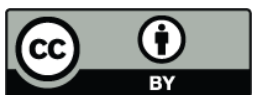

Correspondence to: C. J. Williams (jason.williams@ars.usda.gov) results demonstrate that snow exerts significant influence on how water is retained within mid-elevation semi-arid catchments and suggest that reductions in annual snowpacks associated with changing climate regimes may strongly influence spatial and temporal soil moisture patterns and catchment physical and biological processes.

\section{Introduction}

Soil moisture exists at a critical nexus between atmospheric and terrestrial hydrologic processes. It occurs as a balance between the competing demands of the atmosphere, vegetation, and gravitational drainage. The spatial and temporal distribution of soil moisture controls numerous catchment processes including runoff generation, groundwater recharge, evapotranspiration, soil respiration, and biological productivity. Understanding the controls on the spatial and temporal variability of soil moisture is an essential step towards developing improved predictive models of catchment processes. A challenge is that the controls on the spatial distribution of soil moisture are combinations of static (e.g. topography, soil properties) and dynamic (e.g. precipitation, antecedent moisture) variables (Reynolds, 1970). The superposition of static and dynamic controls can lead to different soil moisture patterns during wetting, draining, and drying periods (Grayson et al., 1997; Grayson and Western, 1998; Western et al., 1999, 2004). For example, Famiglietti et al. (2008) summarized numerous studies illustrating how the spatial variability of soil moisture can increase or decrease with the spatial mean moisture content depending

Published by Copernicus Publications on behalf of the European Geosciences Union. 
on relationships between soils, vegetation, topography, antecedent moisture content, and scale.

Approaches to explain the catchment-scale spatial variability of soil moisture have been motivated primarily by the need to understand runoff generation or other "wet" hydrologic processes invoking the concept that soil moisture moves laterally according to topography (e.g. Anderson and Burt, 1977; Beven and Kirkby, 1979; O'Loughlin, 1981; Burt and Butcher, 1985; Moore et al., 1988; Barling et al., 1994; Brocca et al., 2007). In semi-arid environments where soil moisture content is commonly too low to drain freely, however, lateral movement of soil moisture may be possible only during brief windows of time (Grayson et al., 1997; Western et al., 1999; McNamara et al., 2005). In these waterlimited environments it is equally important to understand how water is retained in a catchment, as well as how it leaves.

Soil moisture variability is directly connected to precipitation variability. The interacting influences of precipitation, soil properties, vegetation, and topography on soil moisture have been extensively investigated (Hawley et al., 1983; Moore et al., 1988; Grayson et al., 1997; Famiglietti et al., 1998; Grayson and Western, 1998; Seyfried, 1998; Western et al., 1999, 2004; Gómez-Plaza et al., 2001; Ridolfi et al., 2003; Tromp-van Meerveld and McDonnell, 2006; Brocca et al., 2007). In snow-dominated mountain regions precipitation does not necessarily enter the soil where it falls, but where it melts. Redistribution of snow by wind and differential melt patterns controlled by elevation, aspect, and vegetation create spatially heterogeneous snow cover that leads to spatially variable soil moisture patterns (Litaor et al., 2008; Seyfried et al., 2009). Few studies have documented how the distribution of snow interacts with other variables to control soil moisture patterns.

Understanding relationships between snow and soil moisture variability is particularly pressing as the western United States is experiencing decreased snowpack in response to climate warming (IPCC, 2007). Twentieth century increases in temperature (e.g. Jones et al., 1999; Brohan et al., 2006) have been accompanied by a shift towards earlier spring snowmelt-driven streamflow (Cayan et al., 2000, Stewart et al., 2005), and substantial declines of April 1 snowpack (Mote, 2003). These changes in snowpack dynamics necessitate understanding how snow impacts the distribution of soil moisture in a catchment in relation to other controlling variables, especially at mid-elevations where annual snowdominated precipitation regimes are expected to change to rain-dominated.

In this study we assess the controls on spatial and temporal near-surface soil moisture variability in a small $\left(0.02 \mathrm{~km}^{2}\right)$ semi-arid mountainous catchment by evaluating the spatial correlations between soil moisture and numerous site characteristics throughout the water year. The aim of this research is to identify catchment properties that best explain the spatial variability of soil moisture during the semi-arid hydrologic seasons. We assess the relative importance of snow with re- spect to other catchment properties on the spatial variability of soil moisture, investigate how that variability changes with mean moisture content, and track the persistence of those controls through a water year. Spatial variability is assessed by correlation analysis, and the temporal persistence of the patterns of variability is assessed by time stability analysis.

\section{Study site and hydrologic setting}

The study was conducted in the Treeline site $\left(0.02 \mathrm{~km}^{2}\right.$, Fig. 1) within the Dry Creek Experimental Watershed (DCEW) near Boise, Idaho. The Treeline site is located at a mean elevation of $1620 \mathrm{~m}$ and has $70 \mathrm{~m}$ total relief. The site trends northwest to southeast, with slopes averaging $30^{\circ}$ over mostly concave and convex angles. The catchment has one main ephemeral channel with five connecting seep channels (Fig. 1). Soils are coarse-textured and shallow $(\sim 0.2$ to $1.3 \mathrm{~m}$ ), derived from weathering of the Idaho Batholith, a biotite granodiorite intrusion 75 to 85 million years in age. Soils are classified as coarse-loamy, mixed mesic Ultic Haploxeroll (Harkness, 1977). Treeline is located in a vegetation transition zone between grass and shrub-lands and the forested regions of the DCEW. The primary vegetation includes sagebrush (Artemisia spp.), forbs, and grasses. Approximately eight mature trees (Pinus ponderosa; Pseudotsuga menziesii) are present as isolated individuals.

Precipitation (annual average $57 \mathrm{~cm}$ ) falls mostly during the cold season, with approximately half the annual precipitation falling as snow (McNamara et al., 2005). Rain-onsnow events are common during the late autumn and early spring seasons. Summer months are hot and dry with infrequent thunderstorm events. Streamflow typically begins in early autumn with the onset of autumn rains, but remains low or episodic with the development of the snowpack. Late autumn and early winter rain-on-snow events and/or complete melt on southerly aspects generate small hydrograph peaks. Snowpack on the northeast facing slope is usually maintained from the onset of snowfall. The annual hydrograph peak usually occurs in March or April depending on the duration of snowmelt (McNamara et al., 2005).

McNamara et al. (2005) described five characteristic soil moisture states/periods for the Treeline site based on observations and simulations: (1) dry, (2) wet-up, (3) wet-low flux, (4) wet-high flux, and (5) drydown. The dry period occurs when evapotranspiration exceeds precipitation and soil moisture is greater in deeper portions of the soil profile. The wetup period begins as autumn rains wet-up the near-surface environment and precipitation exceeds evapotranspiration. The wet-up period is marked by a rapid rise in soil moisture at soil depths from the surface to $45 \mathrm{~cm}$ at most points in the catchment. As the autumn season progresses to winter, precipitation shifts from rainfall to snowfall. Precipitation water is stored in the snowpack and water input to the soil is reduced (wet-low flux period). If the onset of a snowpack 


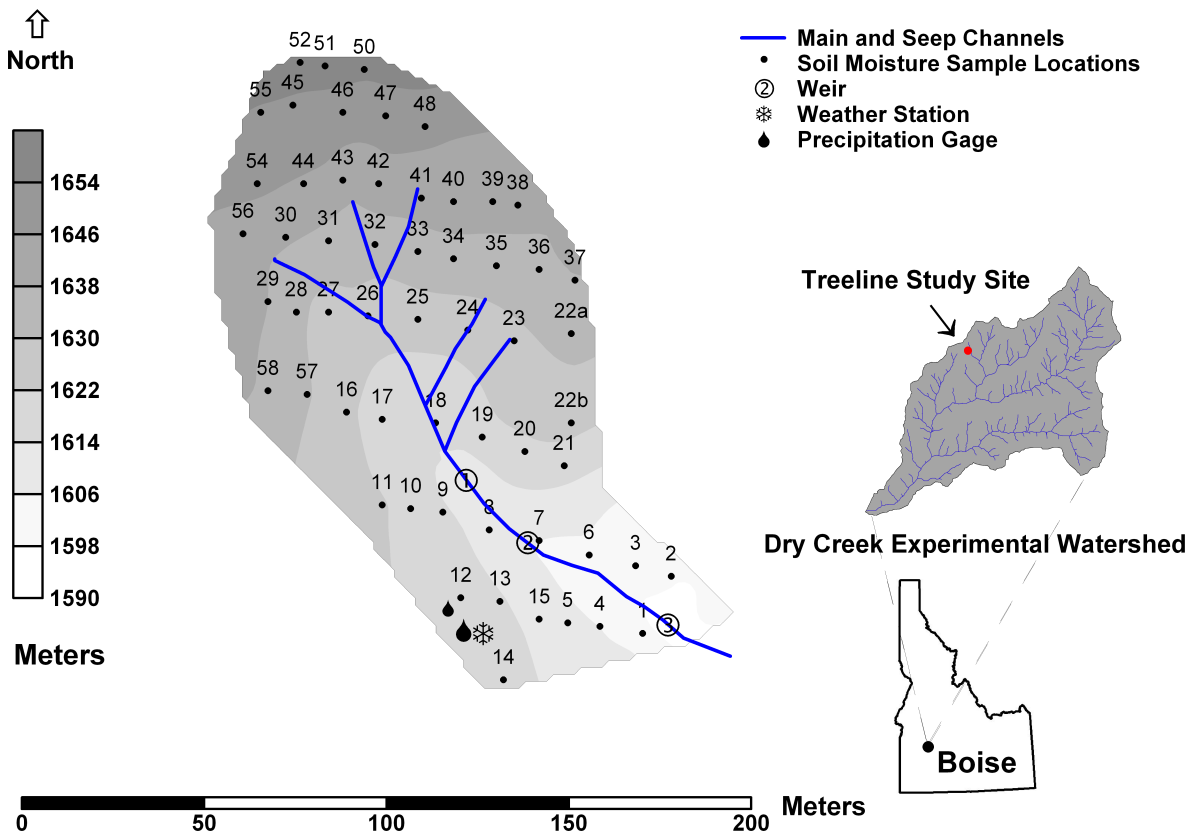

Fig. 1. Location and instrumentation of the Treeline study site in the Dry Creek Experimental Watershed, near Boise, Idaho, USA.

occurs before the wetting front reaches the soil bedrock interface dry soil at depth can persist through the winter until the snowpack melts. The wet-high flux period begins as the snowpack ripens and continues through the snowmelt period. Soil moisture during the wet-high flux period increases to maximum annual levels throughout the soil profile. The drydown period begins after complete melt of the snowpack and water input is reduced below evapotranspiration. Soil moisture during the drydown period declines first near the surface and more gradually and delayed at depth. Field capacity at the site is approximately $0.18 \mathrm{~m}^{3} \mathrm{~m}^{-3}$ volumetric soil moisture content (McNamara et al., 2005).

\section{Methods}

\subsection{Site characterization}

A $10 \times 20 \mathrm{~m}$ study grid (57 sampling points) was established to characterize catchment physical (topography and soils) and biological characteristics (vegetation) (Fig. 1). Site topography (aspect, elevation, and slope), soil texture, soil depth, and percent live canopy cover were measured at each grid point. Topographic details from each grid point were used in conjunction with 156 additional survey points to generate a digital elevation model (DEM). The percent coarse $(>2.00 \mathrm{~mm})$, sand $(<2.00 \mathrm{~mm}$ and $>0.05 \mathrm{~mm})$, and fine $(<0.05 \mathrm{~mm})$ soil fractions over 0 to $30 \mathrm{~cm}$ soil depth were determined by sieving core soil samples (mean sample size $4.7 \mathrm{~g}$ ) from each point. Soil depth was determined by pounding a steel rod through the soil profile to refusal. Percent live canopy cover was measured during the spring, summer, and autumn seasons using the Daubenmire method (1959) within $100 \times 70 \mathrm{~cm}$ rectangular plots at each study grid point. The autumn season vegetation survey occurred near the beginning of the winter season. Therefore, vegetation measured during the autumn survey was assumed equivalent to that of the winter season. Land surface convexity, concavity, and plan, mean, longitudinal, and cross-section curvature were determined by digital terrain analyses of the survey DEM using Landserf 2.1 (Wood, 1996). Upslope contributing areas for each study grid point were calculated using the D-infinity method within TauDEM (Tarboton, 2003). Snow density and snow water equivalent (SWE) at the time of maximum snow depth were determined by snow survey with Mt. Rose snow samplers.

Meteorological data (precipitation, snow depth, air temperature, relative humidity, wind speed, wind direction, and incoming solar radiation) are collected at a meteorological station located near a ridgeline on the northeast-facing slope between the middle and lower weirs (Fig. 1). Rainfall and snowfall are measured in a weighing-bucket gauge shielded on a post $1.5 \mathrm{~m}$ above the ground surface. Hourly snow depth is monitored near the meteorological station using a Judd sonic depth sensor. Rainfall and snowfall during the study year were approximately $116 \%$ of average recorded from 1999 through 2006. Soil moisture near grid location 9 is monitored in 15 min intervals with a Campbell Scientific TDR100 (time domain reflectometry) system at depths of 5, $15,45,75$, and $105 \mathrm{~cm}$. Data from the meteorological station and TDR100 system are collected with Campbell Scientific CR10X dataloggers. Streamflow at three v-notch weirs is determined from stage-discharge relationships established for 
each weir by timing the period required for discharge to fill a cylinder of known volume. Stage in the ponds behind each weir is monitored hourly by capacitance rods.

Spatial soil moisture measurements were obtained using a portable TDR unit along the study grid. The portable TDR unit consisted of a TDR100 wave generator, laptop computer, PC-TDR software (cable tester), RG-58 TDR connection cable, and TDR probe. The PC-TDR software calculates the soil dielectric constant from wave travel time, and determines the respective soil moisture content $\left(\mathrm{m}^{3} \mathrm{~m}^{-3}\right)$ using a specified calibration equation (Ledieu et al., 1986). Laboratory testing with ten soil samples from Treeline found volumetric soil moisture content from the portable TDR unit was very strongly correlated $\left(r^{2}=0.99\right)$ with known soil moisture over a range 0.05 to $0.40 \mathrm{~m}^{3} \mathrm{~m}^{-3}$ (Williams, 2005), as is expected for soils with low salinity, clay and organic matter content (Jones et al., 2002). Point near-surface soil moisture measurements along the study grid were taken by vertically inserting the TDR probe into the upper $30 \mathrm{~cm}$ of the soil profile. When a snowpack was present, snow was carefully removed from the immediate sampling area soil surface. Snow removed from the sampling area was replaced following sampling and allowed to accumulate between sampling dates. Near-surface soil moisture was measured at each point on the study grid on 38 occasions between April 2003 and June 2004. Sampling occurred approximately twice monthly during summer 2003, bi-weekly during autumn 2003, and twice weekly during winter and spring 2004. Near-surface measurements recorded from January through February of 2004 were removed from the data set due to instrument error.

\subsection{Spatial variability of soil moisture}

The extent of influence of several spatially variable site characteristics on point mean near-surface soil moisture was tested with the Pearson correlation coefficient, $r$. Site characteristics included aspect; concavity and convexity; distance to divide; distance to stream; elevation; maximum snow depth; percent coarse, sand, and fine soil fractions; percent live vegetative cover (by season); plan, profile, mean, longitudinal, and cross-section curvature; slope; soil depth; snow density at maximum snow depth; snow water equivalent (SWE) at maximum snow depth; and upslope contributing area. The null hypothesis was that soil moisture is not related to a particular site characteristic index or value, i.e. the specific site characteristic exerted no control on the distribution of soil moisture at the site, and $r=0$. For positive $(+)$ or negative ( - ) correlations, the statistical significance of $r$ was determined for $\alpha=0.05$.

\subsection{Temporal variability of soil moisture}

Time stability analysis (Vachaud et al., 1985; Grayson and Western, 1998; Grant et al., 2004) was used to assess how individual measurement locations deviated from catchment mean soil moisture conditions. The time stability analysis required, for each sample location on each sampling date, calculation of soil water storage $\left(S_{i j}\right)$ at the greatest common depth $(30 \mathrm{~cm})$ and the relative difference $\left(\delta_{i j}\right)$ in soil water storage and catchment mean near-surface soil water storage $\left(\bar{S}_{j}\right)$. Soil water storage at each sample location $i$, at time $j$, was calculated as:

$S_{i j}=\theta_{i j} z_{i j}$

where $\theta_{i j}$ and $z_{i j}$ represent measured near-surface soil moisture content and the thickness of the sampled soil profile $(30 \mathrm{~cm})$ respectively at location $i$, time $j$. The relative difference $\left(\delta_{i j}\right)$ between soil water storage $\left(S_{i j}\right)$ at a location $i$ and the catchment mean near-surface soil water storage $\left(\bar{S}_{j}\right)$ observed at time $j$ was computed as:

$\delta_{i j}=\frac{S_{i j}-\bar{S}_{j}}{\bar{S}_{j}}$

The mean relative difference $\left(\bar{\delta}_{i}\right)$ for all sample times was calculated as:

$\bar{\delta}_{i}=\frac{1}{m} \sum_{j=1}^{m} \delta_{i j}$

where $m$ is the number of sampling times.

Time stability between successive measurement dates was determined by a Spearman correlation coefficient $\left(r_{s}\right)$ described by Vachaud et al. (1985):

$r_{s}=1-\frac{6 \sum_{i=1}^{n}\left(\left(R_{i}\left(j_{2}\right)\right)-\left(R_{i}\left(j_{1}\right)\right)\right)^{2}}{n\left(n^{2}-1\right)}$

where $n$ is the number of observations, $R_{i}\left(j_{2}\right)$ is the rank of $S_{i j}$ at location $i$, time $j_{2}$, and $R_{i}\left(j_{1}\right)$ is the rank of $S_{i j}$ at location $i$, time $j_{1}$. The time stability between two sampling dates becomes more stable as $r_{s}$ approaches 1, with perfect time stability occurring where $r_{s}=1$ (Vachaud et al., 1985).

In addition to time stability between successive sampling times, we are interested in the tendency for locations to retain their relative wetness ranks throughout the year. Grayson and Western (1998) suggested that the standard deviation of the relative difference for a sample location, $\sigma\left(\delta_{i}\right)$ is an indicator of time stability, reasoning that locations with low values retain similar relative differences through time. The standard deviation is calculated as:

$\sigma\left(\delta_{i}\right)=\sum_{j=1}^{m}\left(\frac{\delta_{i j}-\bar{\delta}_{i}}{m-1}\right)^{1 / 2}$

where $\mathrm{m}$ is the number of sample times. It is possible that extreme wet or dry locations have high $\sigma\left(\delta_{i}\right)$ values while retaining stable wetness ranks. To identify these locations we used a rank change index (RCI). The RCI for a location 
$i$ is the sum of the absolute values of the differences in rank between successive measurements:

$\mathrm{RCI}_{i}=\sum_{j=1}^{m}\left(\left|R_{j}-R_{j-1}\right|\right)$

where $m$ is the number of sample dates, and $R$ is the rank of the location's soil moisture content relative to all locations on date $j$.

\section{Results}

To assess the relative importance of snow on the spatial variability of soil moisture we first present a summary of the surface characteristics of the catchment. Second, we explain the temporal soil moisture patterns in a single soil pit with continuously logging sensors to illustrate the general behavior through different hydrologic seasons. Third, we relate the spatial soil moisture patterns to the temporal patterns with particular emphasis on how the spatial variability changes with the mean. Fourth, we summarize the temporal stability, or the tendency for any position to maintain its wetness rank relative to the mean. Finally we relate these spatial and temporal patterns to surface characteristics.

\subsection{Surface descriptions}

The catchment contains aspects from 48 to $226^{\circ}$ and encompasses land surface slopes of 7 to $46^{\circ}$ (13 to $\left.82 \%\right)$. Mean soil depth for the catchment is approximately $0.46 \mathrm{~m}$ (range is 0.2 to $1.3 \mathrm{~m}$ ) with the soil depth generally increasing from the catchment divide towards the channel (Fig. 2a). The deepest soils and snow drifts occur mid-slope on the southwestern part of the catchment (Figs. 2a and b). Snow accumulation (Fig. 2b) and snow water equivalent during this study were generally greater in the southwest and central portions of the catchment, with some drifts forming on leeward sides of small seep channels. The coarse, sand, and fine soil fractions were 19, 76, and 6 percent, respectively. Exposed surface rock was found in the northeastern most part of the catchment and along the eastern boundary, and the sandiest soil was located in the upper third of the catchment (Fig. 2c), immediately upslope of seep channel junctions. Field observations identified an illuvial clay layer of variable depth immediately above the soil-bedrock interface.

Average percent live canopy cover through the autumn and winter seasons was approximately $9 \%$. Live canopy cover averaged approximately $35 \%$ and $45 \%$ for the spring and summer seasons respectively. Leaf out began at the site in mid-March. Early spring season forbs and grasses reached heights of $7 \mathrm{~cm}$ by late March and shrub leaves began budding by early April. By late April grasses reached approximately $15 \mathrm{~cm}$ in height and overall canopy cover increased beyond $20 \%$. By late May grasses at the site were approximately $25 \mathrm{~cm}$ in height and shrub cover neared its maximum.
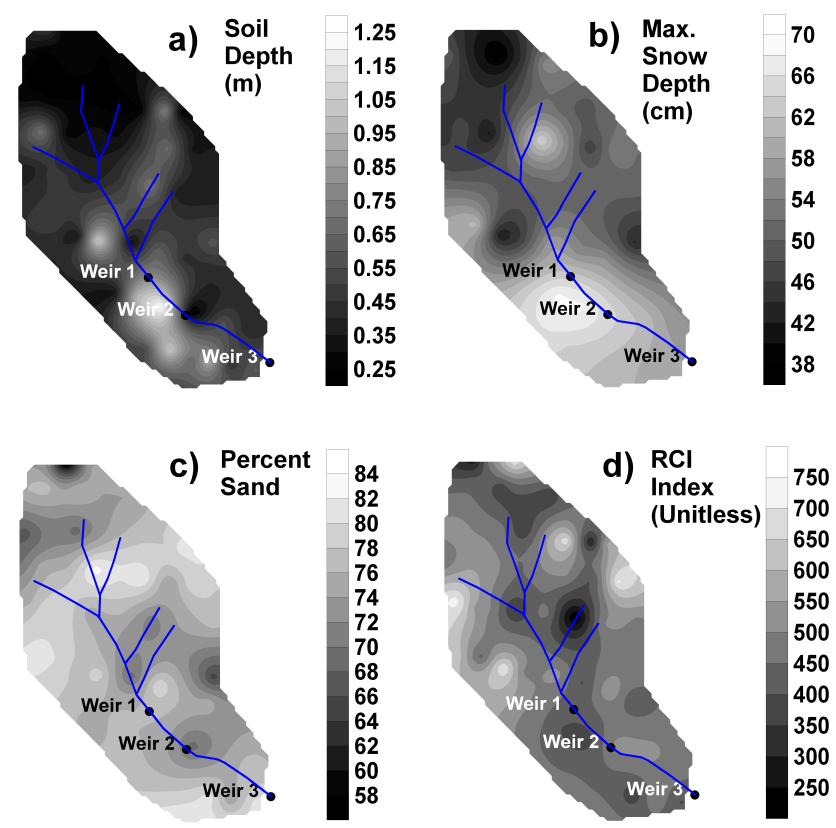

Fig. 2. Kriged maps (calculated with Surfer 8.0, Golden Software) of soil depths (a), snow depths at maximum accumulation (b), percent sand contents of the soil (c), and the rank change index (RCI, d) for the changes in the rank of soil moisture mean relative difference measured at 57 points of the Treeline study grid.

Plant cover reached its maximum in mid-June before some species began senescence.

\subsection{Temporal soil moisture patterns at a soil profile}

The annual soil moisture behavior was similar to that reported in McNamara et al. (2005) with relatively stable dry and wet periods separated by transition seasons (Fig. 3). During the dry period, soil moisture ranged from 0.04 in the nearsurface to $0.07 \mathrm{~m}^{3} \mathrm{~m}^{-3}$ at depth. As the autumn rains commenced in December 2003 (Fig. 3a), soil moisture increased above field capacity to approximately $0.21 \mathrm{~m}^{3} \mathrm{~m}^{-3}$ (Fig. 3b) at a depth of $75 \mathrm{~cm}$. However, soil moisture at the base of the soil profile $(>75 \mathrm{~cm})$ remained near $0.07 \mathrm{~m}^{3} \mathrm{~m}^{-3}$ for an additional 25 days after the wet-up at $75 \mathrm{~cm}$. McNamara et al. (2005) credited this phenomenon to the transition from precipitation as rain to snow. When precipitation phase shifts from rain to snow in early winter, most storage occurs in the snowpack and soil water input rate is low until snow melts. Soil moisture at $105 \mathrm{~cm}$ reached the wet stable state under a continuous snowpack in mid-January (Fig. 3). It is important to note that the soils depicted in Fig. 3 are the deepest in the catchment. It is likely that bedrock wetting and lateral sub-surface flow occur earlier where soils are shallow.

In March of 2004, air temperature increased above $0^{\circ} \mathrm{C}$ and precipitation shifted back to rain (Fig. 3a). The snowpack was completely melted by mid-March. By late May water input at the site decreased dramatically while 


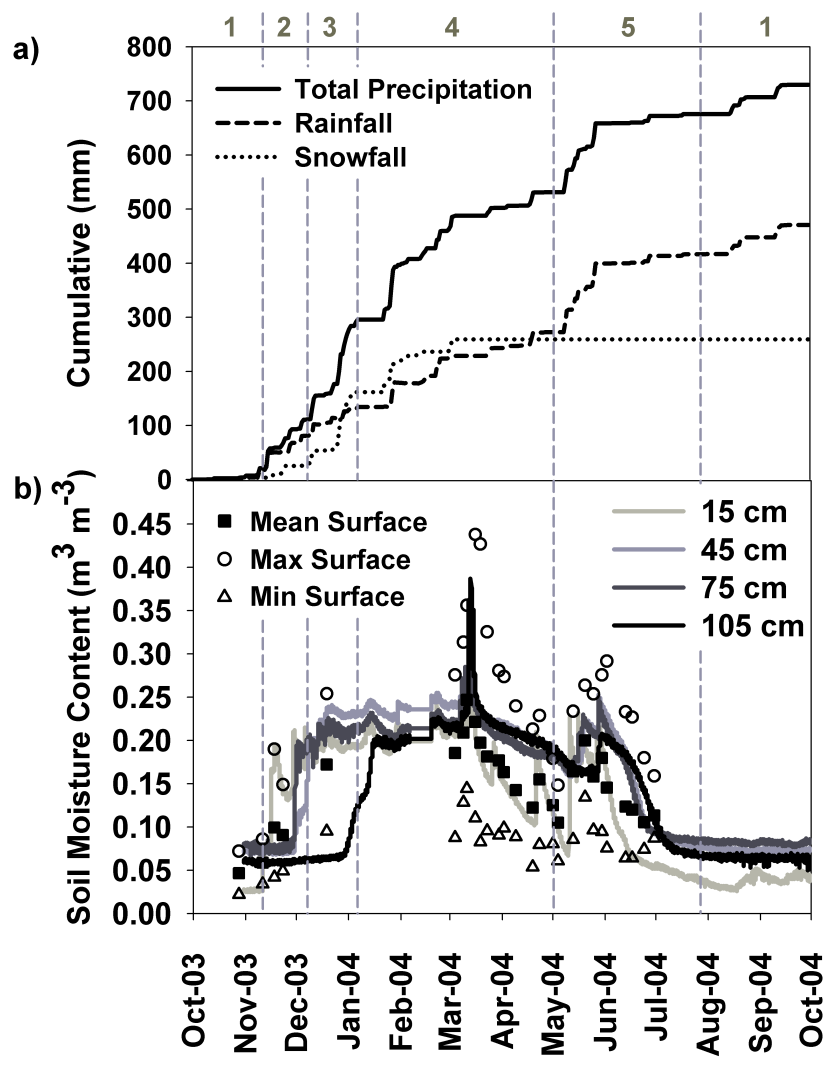

Fig. 3. Timing of the precipitation (a) and the dry -1 , wet-up -2 , wet-low flux -3 , wet-high flux -4 , and drydown -5 characteristic soil moisture periods (b) observed at Treeline during the 2003/2004 water year. The curves show soil moisture contents observed at 15 , 45,75 , and $105 \mathrm{~cm}$ depths in a time domain reflectometry (TDR) instrumented soil pit of a deep soil profile. Symbols depict mean, maximum, and minimum near-surface measurements (b) recorded at soil moisture sampling locations (using portable TDR) along the study grid.

evapotranspiration demands remained high. Near-surface soil moisture content peaked near $0.25 \mathrm{~m}^{3} \mathrm{~m}^{-3}$ in midMarch, declined to $0.07 \mathrm{~m}^{3} \mathrm{~m}^{-3}$ in late May following snowmelt, then returned to $0.22 \mathrm{~m}^{3} \mathrm{~m}^{-3}$ following atypically intense spring rains after the wet-high flux period (Fig. 3b). Deep soil moisture peaked near saturation $\left(0.37 \mathrm{~m}^{3} \mathrm{~m}^{-3}\right)$ during melt in March and gradually declined before rising again to approximately field capacity $\left(0.22 \mathrm{~m}^{3} \mathrm{~m}^{-3}\right)$ following the late spring rains (Fig. 3b). Drydown followed the unusually high May rainfall and continued through June (Fig. 3b). By the end of the drydown period near surface soil moisture content fell sharply to $0.07 \mathrm{~m}^{3} \mathrm{~m}^{-3}$ and deep soil moisture decreased to $0.08 \mathrm{~m}^{3} \mathrm{~m}^{-3}$ (Fig. 3b).

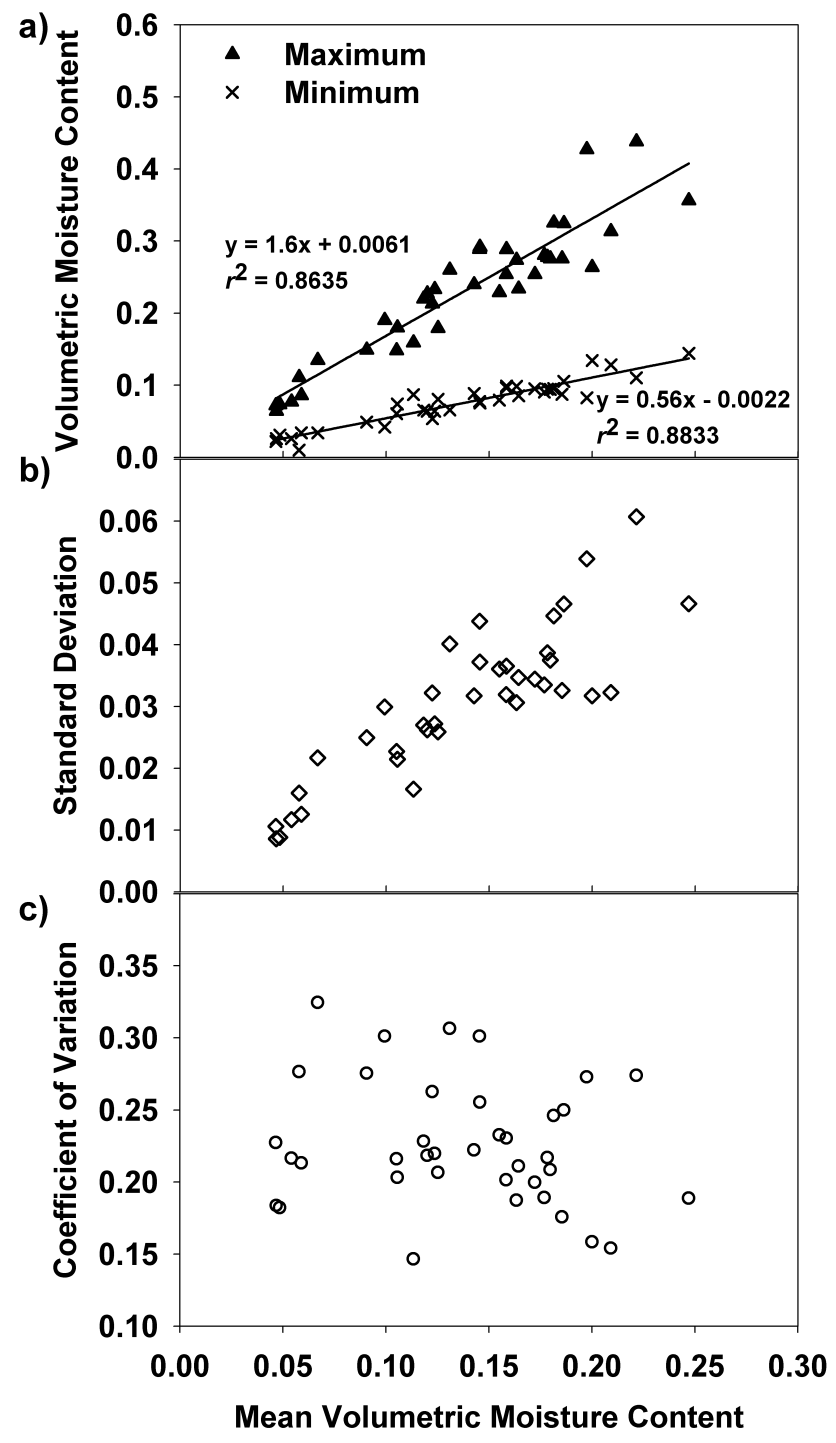

Fig. 4. Maximum and minimum (a), standard deviation (b), and coefficient of variation (c) of soil moisture contents $\left(\mathrm{m}^{3} \mathrm{~m}^{-3}\right)$ for individual sampling dates versus the respective sampling date site mean volumetric soil moisture content $\left(\mathrm{m}^{3} \mathrm{~m}^{-3}\right)$.

\subsection{Relations between spatial variability, temporal vari- ability, and mean moisture content}

The spatial mean, maximum, and minimum moisture contents display similar temporal patterns as the point-scale moisture contents (Fig. 3b). The maximum, minimum, range, and standard deviation of moisture content clearly increased with the mean (Fig. 4a and 4b). The relative variability as measured by the coefficient of variation (Fig. 4c), however, did not show any clear trend with spatial mean moisture content indicating that the distribution of soil moisture scales with the mean. These results are in contrast with Famiglietti et al. (1999) and Hupert and Vanclooster (2002), who 
showed decreases in the standard deviation and the coefficient of variation with increasing mean moisture content, but in agreement with Western and Grayson (1998) and Famiglietti et al. (1998).

Whereas Fig. 4 illustrates how the spatial variability of moisture changes in time, with moisture content as a proxy for time, the RCI (Eq. 6) reveals how the temporal variability varies in space. The RCI is highest for locations with mean relative difference (MRD) close to zero and lowest for extreme wet and dry locations (Fig. 5a) suggesting that extreme values are the most temporally stable relative to wetness rank. However, the extreme wet locations also have the highest MRD standard deviations (Fig. 5b), indicating high moisture fluctuations. The fluctuations, however, occur within relatively wet and dry moisture contents causing the low RCI values.

Mean relative differences of soil moisture exhibit seasonality among the wet $(\mathrm{MRD}>0.10)$ and dry $(\mathrm{MRD}<-0.10)$ points (Fig. 6). The extent of spatial-seasonal controls are underscored by a persistent MRD state (dry) at point 20 solely (Fig. 6). Within the wet-dry seasons, wet spots tended to stay wet and dry spots tended to stay dry relative to the mean (Fig. 6). Soil moisture contents at upper elevation sample locations were generally less than the site mean soil moisture content with exception of the wet-up season (Fig. 6). These locations are typified by low vegetative cover, shallow soils, and lower snow accumulation than the remainder of the catchment. These data suggest the upper elevation locations exceed site mean soil moisture conditions solely during the wet-up period (Fig. 6) when autumn rains occur. Positive soil moisture MRD values occur primarily in the central portion of the catchment, near the stream channel and ephemeral seeps (points 1, 8, 18, 23, 24, 25, 26, 41) and at locations subject to the greatest contributions of snow water input (points 4, 5, 9, 13, 14, 15, 57, 58). Positive MRD is most pronounced near the channels early during the wet-high flux season, but also occurs at locations where snow accumulates as the catchment soil moisture declines with seasonal drydown (4 May through 2 June, Fig. 6).

\subsection{Spatiotemporal correlations with soil moisture}

Distance to divide showed the highest $(+0.64$ on 9 April 2004) and most consistent correlation with soil moisture, with significant positive correlations with soil moisture on 27 of the 38 sampling dates. Other variables that were significantly, although weakly, correlated (positive $[+]$ or negative [-]; number of significant observations) with soil moisture at least 10 times include snow density at time of maximum depth $(+; 20)$, elevation $(-; 19)$, SWE at time of maximum depth $(+; 19)$, northing $(-; 18)$, soil depth $(+; 18)$, percent coarse $(-; 15)$, distance to stream $(-; 13)$, percent sand $(+; 13)$, and snow depth at time of maximum depth $(+; 13)$. In all cases the correlation coefficients show clear temporal trends and maximum correlations for the wet pe-

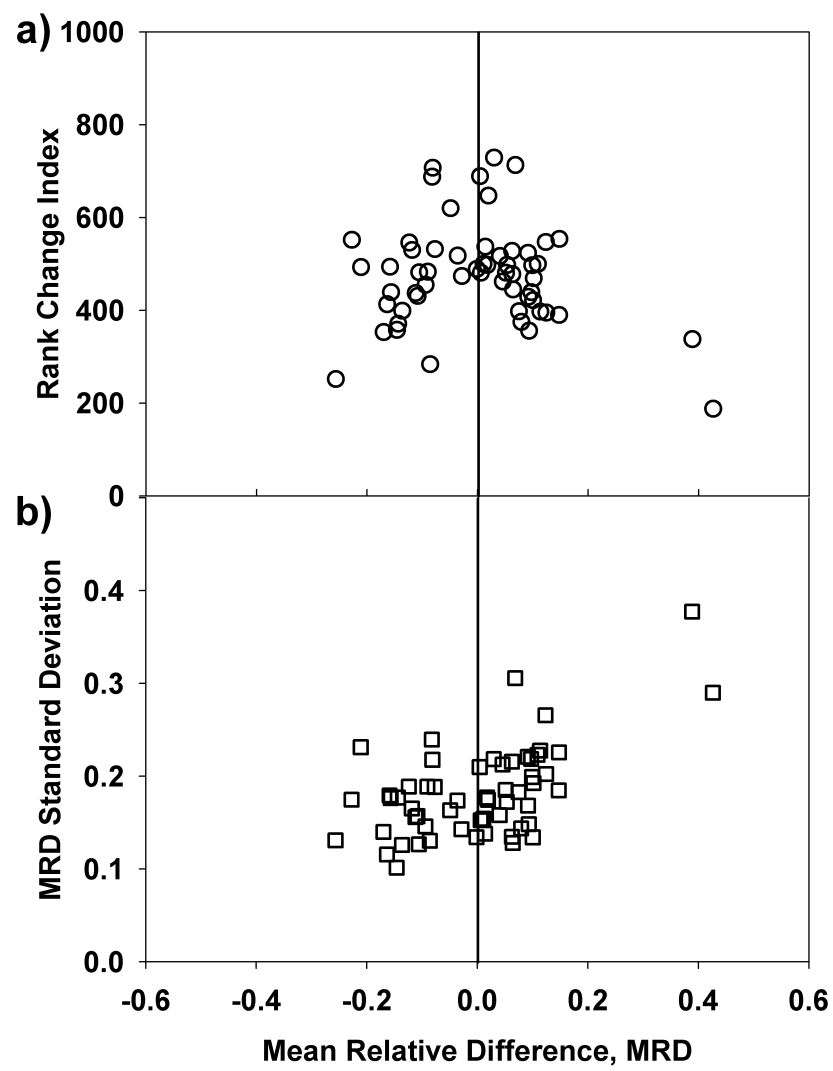

Fig. 5. Relationships of the rank change index (a) and mean relative difference (MRD) standard deviation (b) with catchment MRD.

riod from mid-April to early-May 2004 (Fig. 7). Following snowmelt, correlations between soil moisture and all tested variables weaken and become insignificant as near surface soil dries. Although our sampling period ended in June 2004, the previous year showed similar patterns with diminishing correlations through summer.

The consistent negative correlations in soil moisture with elevation and northing, and positive correlations with distance to the divide indicate drier soil conditions at sample locations in the northern-most portion of the catchment and at higher elevations. The correlation results are similar to patterns in mean relative differences (Fig. 6) indicating sample locations in the higher elevations and along ridges consistently represent soil moisture conditions drier than the site average soil moisture content except during the wet-up period. The spatiotemporal correlations for soil moisture and snow variables are further supported by mean relative difference data that indicate wetter conditions in the locations that accumulate snow and maintain a winter season-long snowpack (Figs. 2b and 6).

The time stability of soil moisture between successive sampling dates followed similar temporal correlation trends as site characteristics correlation coefficients (Fig. 7). Spearman correlation coefficients $\left(r_{s}\right.$, Eq. 4) were least (below 

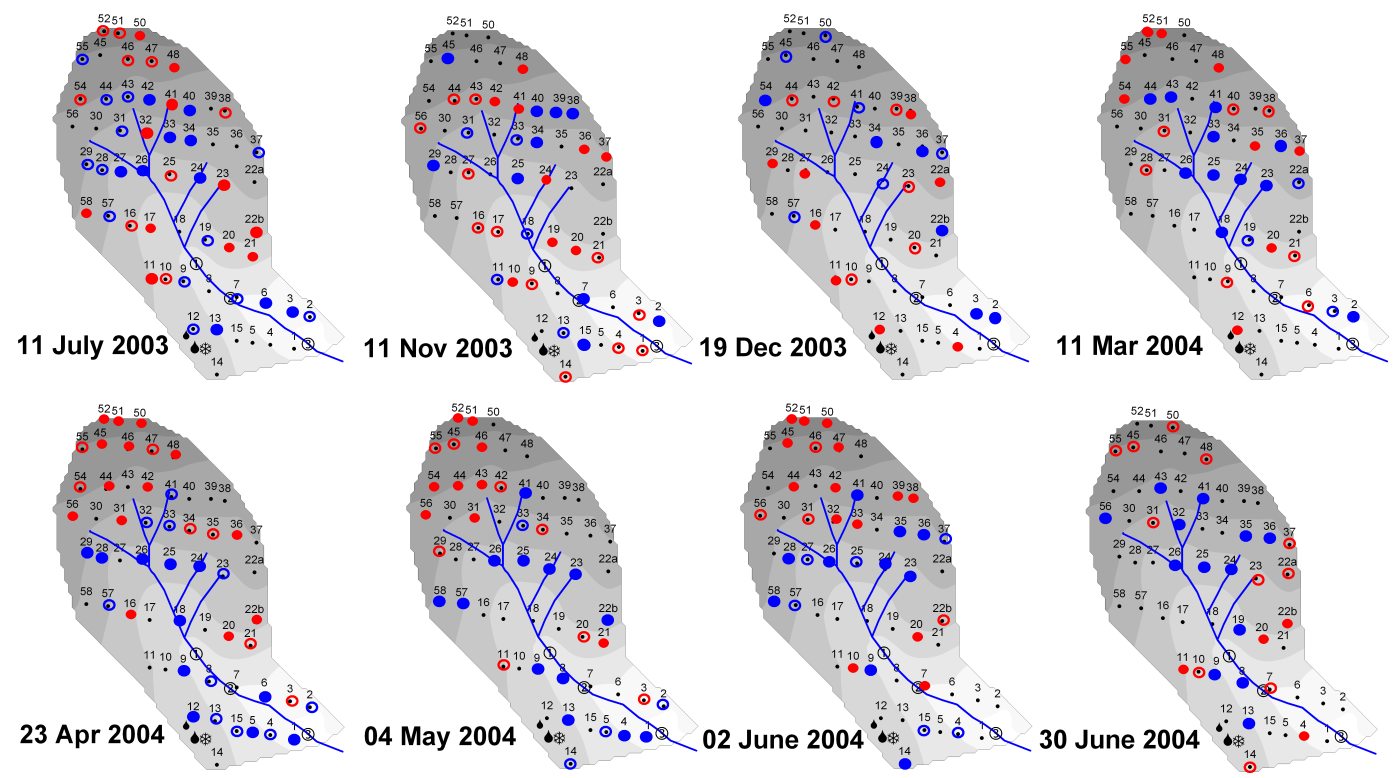

Fig. 6. Mean relative difference (MRD) in soil moisture content by sampling location for representative dates during dry (11 July 2003), wet-up (11 November 2003, 19 December 2003), wet-high flux (11 March 2004, 23 April 2004), initial drydown (4 May 2004), following spring rain (2 June 2004), and final drydown (30 June 2004) periods. Points having positive MRD are indicated in blue, negative MRD in red. Relative differences from the mean greater than 0.10 are indicated by open circles, greater than 0.20 indicated by filled circles.

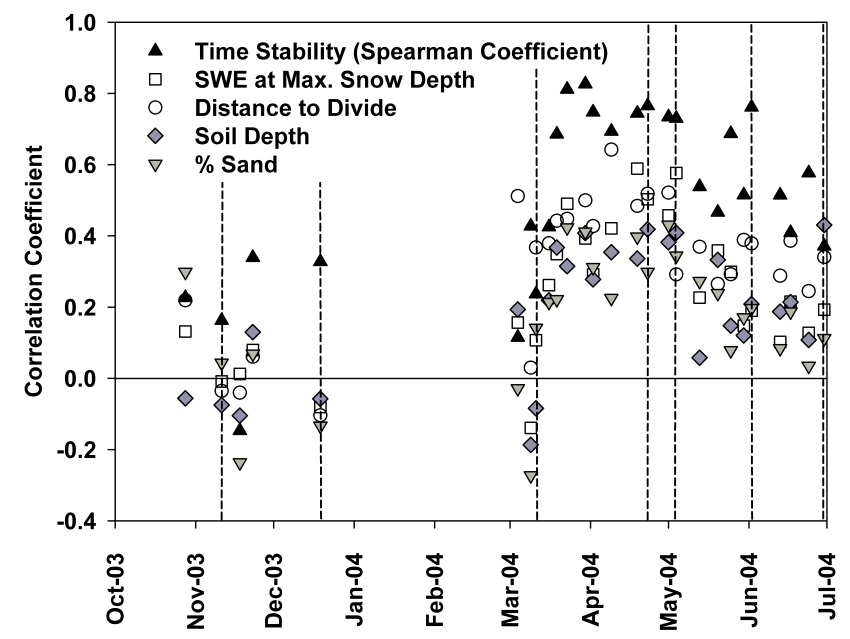

Fig. 7. Pearson correlation coefficients, $r$, of measured point soil moisture contents and site characteristics and Spearman correlation coefficients, $r_{s}$, for temporal stability between successive soil moisture sampling periods. Dashed lines indicate dates selected as representative of hydrologic states.

0.40 ) during the drier periods of the year and were consistently between 0.65 and 0.82 through most of the wet period. Time stability between sampling was inconsistent during drydown and decreased to near 0.40 by the beginning of the dry period in 2004 (Fig. 7). These data suggest near perfect time stability of soil moisture during and immediately following snowmelt (wet period) and indicate this pat- tern breaks down during the drier periods of the year when transpiration exceeds water input. Two surface characteristics were significantly correlated $(\alpha=0.05)$ with the RCI. Soil depth was negatively correlated $(r=-0.36)$ indicating that locations with deep soils tend to maintain their wetness relative to the mean. Distance to stream was positively correlated $(r=0.30)$ indicating that points closer to ridges experience larger or more frequent wet/dry cycles. These patterns are evident on Fig. 2d. The highest RCI values occur on the ridges and the lowest in the ephemeral channels, while intermediate values tend to correspond to soil depth.

\section{Discussion}

Complex terrain influences on the spatial patterns of snow accumulation and melt explain the spatiotemporal patterns of soil moisture at the Treeline catchment throughout most of the year. Three distinct spatial soil moisture trends emerged: (1) an early wet period near-saturation sub-surface source area near the channel head (Fig. 6, 11 March 2004), (2) late wet-period near-saturation conditions in the southwestern portion of the catchment (Fig. 6, 23 April 2004), and (3) early wet-up period spatially heterogeneous soil moisture conditions (Fig. 6, 11 November-19 December 2003). The first two result from topographically controlled spatially variable snow accumulation and melt and lateral redistribution of snow water input. They propagate a spatial soil moisture pattern that persists from late wet-up through summer dry period (Fig. 6). The third pattern results from the differential 
draining/storage and evapotranspiration of wet season soil water input and heterogeneous processing of autumn rainfall at the onset of the hydrologic year (Williams, 2005).

The centrally located sub-surface source area (Fig. 6, 11 March 2004) forms from the convergence of lateral and vertical flow sources of snowmelt input at the base of shallow soil profiles (Fig. 2a) in the northern portion of the catchment (Williams, 2005). Snowfall is generally uniform over the catchment, but aspect facilitates frequent melting of the snowfall upslope of and adjacent to the channel head (Williams, 2005). Soil water input from the snowmelt events exceeds field capacity in these shallow $(<30 \mathrm{~cm}$ deep) soils and the threshold for lateral flow is reached (McNamara et al., 2005). The combination of shallow soils and sloping terrain result in lateral routing of soil water in the profile and along the soil-bedrock interface (McNamara et al., 2005; Williams, 2005). The lateral flow convergence with vertical snow water input near the channel head fuels development of a near-saturated sub-surface source area (Williams, 2005). Grayson et al. (1997) and Western et al. (1999) reported similar patterns of transition from dry to wet conditions at sites in Australia. Both studies observed wetter conditions in areas of high local convergence during the dry to wet transition period, indicating topographic redistribution of soil moisture. Anderson et al. (1997) noted a similar source area responsible for streamflow initiation in a steep unchanneled basin in the Oregon Coast Range, USA. Lateral flow through a thin upper-bedrock layer intersected soil water infiltrating vertically in the soil profile near the channel head. The combined flow paths developed a variable sub-surface source area that dictated streamflow generation. We suggest development of a similar sub-surface source area in this study (Fig. 6, 11 March 2004), observed by Williams (2005), occurs due to the topographic controls on snowmelt and subsurface routing of snow water input early in the hydrologic year.

Storage of water in the snowpack delays soil profile wetting in the southwestern portion of the catchment (McNamara et al., 2005). Snow accumulation during the wet-up and wet-low flux periods is substantially greater in the southwestern portion of the catchment (Fig. 2b). Northeast aspects in this location receive less solar radiation than the south-facing slopes in the northern portion of the catchment, upslope of and near the channel head, and exhibit fewer melt events in autumn and early winter. In the southwestern portion of the catchment, stored water in the snowpack is released into the soil profile during the wet-high flux period (McNamara et al., 2005; Williams, 2005) and increases soil moisture contents above the catchment mean soil moisture content (Fig. 6, 23 April 2004). Wet conditions in this location and near the channel head persist into the dry period (Fig. 6) until evapotranspiration demands exceed water input (Williams, 2005) and lateral flow discontinues (Grayson et al., 1997; Western et al., 1999; McNamara et al., 2005). Soils in the northern portion of the catchment dry out first in the absence of snow water input (Fig. 6). Spatially heterogeneous soil draining and evapotranspiration demands during the summer dry period gradually deplete soil water and facilitate spatially variable, but dry, soil moisture conditions (Williams, 2005). The heterogeneous nature of soil moisture patterns in the ensuing autumn wet-up period are likely associated with spatially variable antecedent soil moisture and processing (interception loss, infiltration/percolation) of uniform rainfall input (Williams, 2005).

Although the static controls on soil moisture and their seasonality observed in this study are similar to those reported by others (Grayson et al., 1997; Western et al., 1999; Gómez-Plaza et al., 2001; Grant et al., 2004; Tromp-van Meerveld and McDonnell, 2006), the reasons for significance are strongly associated with static influences on snow distribution and melt. Significant correlations of soil moisture with aspect and topography variables during wet-up can be explained by the influence of these characteristics on early season snowmelt and sub-surface soil water routing in the northern portion of the catchment. Wetter soil moisture conditions that developed in the north-central portion of the catchment (sub-surface source area) during this period (Fig. 6) resulted in hydrological processes commonly observed in more humid to semi-humid environments (Anderson and Burt, 1977; Beven and Kirkby, 1979; O'Loughlin, 1981; Burt and Butcher, 1985; Moore et al., 1988; Barling et al., 1994; Brocca et al., 2007). Significant negative correlations of soil moisture with northing, elevation, and distance to the stream and positive correlations with distance to divide, snowpack variables, and soil depth during the ensuing wet-high flux period are explained by the distribution of available water (snowpack and soil water storage). Snowpack, soil depth and available soil water (sub-surface source area) were generally greater at lower elevations (decreasing northings) and farther from the slope divide. Positions near the slope divide are often windswept of snow or experience early season melt due to intense solar radiation. The ability of the distance to divide variable in this study to represent available water input throughout the year, both the early season lateral flow and the late season snow water input, storage, and lateral flow, explains its more significant correlation with overall soil moisture trends as compared with snow and soil variables. These correlations suggest the spatial domain of the dynamic influence of snowmelt on soil moisture patterns is dependent on how static variables like slope position and orientation influence snowpack development and retention of snow and early season meltwater (Litaor et al., 2008).

Clearly, the spatial patterns of soil moisture in this study arise from the spatial variability of input from snowmelt, the topographic controls on the redistribution of soil moisture during wet periods, and the properties of soil that promote water retention. The relationships between these variables make it difficult to determine the effect of any one variable, or to identify spurious correlations. For example, hillslope position and snow quantity are both correlated with 
the spatial distribution of soil moisture, as well as to each other. While it is possible to explain soil moisture patterns as a result of either variable independently, they likely arise from interactions of the two. Lateral moisture redistribution in the near surface can explain the correlations between soil moisture and slope position. Conversely, this correlation could arise from redistribution of snow downslope, thereby strengthening the relationship between snow and soil moisture. Regardless, it is evident that the spatial distribution of snow directly impacts the spatial and temporal patterns of soil moisture.

We suggest that variable snow distribution coupled with the high relief and variable soil depths in small mountain watersheds imparts a signature of variability on soil moisture during snowmelt that persists even through the dry periods. This idea is supported by the following observations: (1) The standard deviation of moisture content scales linearly with the mean while the coefficient of variation remains relatively stable (Fig. 4), (2) $\mathrm{SWE}_{\max }$, distance to divide, and soil depth are all significantly correlated with moisture content from early winter through the dry periods of the year, and (3) wet and dry points within the watershed tend to maintain their rank, with exception of the autumn rainfall period. Further, the positive relationship between the mean and the standard deviation of moisture content exists during discrete wetting and drying periods as well as during prolonged stable dry periods (data not shown). That is, no threshold moisture content is reached at which the variability-mean moisture content relationship changes, such as has been observed or modeled in many other studies (Famiglietti et al. 2008).

Several studies have documented increases in soil moisture variability with increases in the mean (e.g., Famiglietti et al., 1999; Hupert and Vanclooster, 2002), while others have documented decreases in soil moisture variability with increases in the mean (e.g. Western and Grayson, 1998). Famiglietti et al. (2008) provides a comprehensive review of these studies as well as an analysis of multiple data sets covering spatial scales from $2.5 \mathrm{~m}$ to $50 \mathrm{~km}$. The contradictory observations concerning how variability changes with mean moisture content have motivated numerous studies to attempt to explain the structure of moisture variability from basic principles (i.e., Albertson and Montaldo, 2003; and Teuling and Troch, 2005). Albertson and Montaldo (2003) suggested that topography controls variance during wet periods, but that the control is diminished during dry periods. They further showed that heterogeneous precipitation fields can either produce or destroy variance depending on background moisture conditions. Teuling and Troch (2005) constructed a hydrologic model that showed the main discriminating factor to determine if variability increases or decreases with mean moisture content is whether or not the soil dries below a critical moisture content, which is controlled by the interaction of soil and vegetation properties with precipitation. Famiglietti et al. (2008) found, on gently sloping rangelands, the standard deviation versus mean soil moisture exhibited a convex upward curve, standard deviation peaked at approximately $0.18 \mathrm{~m}^{3} \mathrm{~m}^{-3}$ mean soil moisture content, and soil moisture variance decreased with increasing mean soil moisture. The decreasing variance with soil moisture contents greater than $0.18 \mathrm{~m}^{3} \mathrm{~m}^{-3}$ was largely due to saturated soil conditions. Soils during the wettest periods of this present study were $50-60 \%$ saturated $\left(0.20-0.25 \mathrm{~m}^{3} \mathrm{~m}^{-3}\right.$ mean soil moisture content, Fig. 4). The coarse grained, well-drained nature of the soils inhibit saturation. It is likely that if soil properties promoted water retention, we might see a decrease in the variance at higher means.

Snowmelt creates heterogeneous precipitation fields in complex terrain due to redistribution by wind and to aspectcontrolled differential melt patterns that do not commonly occur for rain except at much larger scales. Numerous studies have shown that heterogeneous rain fields create soil moisture variability at large scales (Famiglietti et al., 2008; Kim and Barros, 2002; Oldak et al., 2002). Snowmelt, therefore, imparts an initial variablity to soil moisture over relatively small scales. This signature is enhanced as soil moisture is redistributed by topographic controls soon after snowmelt. Water migrates downslope where snow and soils tend to be deeper. Deep soils store moisture against evapotranspiration during dry periods. We suggest when static landscape properties are strong sources of variability (topography, slope position, soil properties) the variability that these properties impose on soil moisture tends to persist.

The influence of snow on soil moisture patterns in this study is consistent with Litaor et al. (2008), but contrasts with Grant et al. (2004). Litaor et al. (2008) studied interrelationships of snow depth, SWE, snow disappearance rate, soil moisture ( $0-15 \mathrm{~cm}$ depth), vegetation, and terrain factors at a mountainous snow-dominated site in Colorado, USA. The study found significant correlations in snow disappearance and SWE and terrain factors that control snow distribution, and soil moisture was significantly correlated with snowfall and terrain. Soil water deficits in windblown areas were offset by rainfall and meltwater sources. Grant et al. (2004) investigated soil moisture patterns in a semi-arid snow-dominated mountainous catchment in Idaho and determined snow exerted little influence on the spatial and temporal variability of soil moisture. The study found percent clay and coarse fragment soil contents exerted the greatest influence (soil water storage) on soil moisture and suggested rapid passing of snowmelt contributions in excess of storage capacity through the sampled portion of the soil profile $(0-$ $75 \mathrm{~cm}$ depth) minimized the influence of snow water input. The stronger influence of snow water input in this study, in contrast with Grant et al. (2004), is attributed to more limited distribution and quantity of snow cover and the temporal variance in spatial snow water input into the soil profile. 


\section{Conclusions}

We have shown that spatial distribution of snow, along with slope position, soil texture, and soil depth, has significant control on the spatial variability of moisture content throughout most of the hydrologic year. These relationships are strongest during the wet period and degrade as the catchment dries. As the catchment cycles through wet and dry periods, the relative spatial variability of soil moisture tends to remain unchanged until the next autumn wet-up period. Further, points in the catchment tend to maintain their wetness rank with respect to the mean, with the exception of ridgetops that wet and drain rapidly. Wet locations tend to remain wetter than average, particularly in deep soils, and dry locations tend to remain dryer than average except during autumn wetup. We suggest that the static properties in complex terrain (slope, aspect, soil depth) impose first order controls on the spatial variability of snow and consequent soil moisture, and that the interaction of dynamic (timing of water input) and static properties propagate that relative constant spatial variability from snowmelt through the annual drying period.

The results suggest that snow, in conjunction with terrain and soil properties, exerts significant control on how water is retained in mid-elevation snow-dominated semi-arid catchments. It is expected that precipitation in mid-elevation mountains such as the Treeline site will transition from snow-dominated to rain-dominated in coming decades. The inference is that significant reductions in snow accumulation will strongly influence the processing of precipitation and the subsequent spatial and temporal distribution of soil moisture within these systems. The impacts of these changing hydrologic patterns on physical and biological processes are not investigated here; however, the implication is a conversion of snow-dominated to rain-dominated precipitation will significantly alter the seasonal availability of soil moisture for other ecosystem processes. Conversion of the precipitation regime at the site studied here would likely facilitate a change in the structure of the vegetative community, a resultant different seasonal organization of soil moisture, and a reduced duration of streamflow through the catchment. Predictive models of such responses will need to incorporate the requisite influences of static and dynamic variables on catchment hydrologic processes.

Edited by: J. Freer

\section{References}

Albertson, J. D. and Montaldo, N.: Temporal dynamics of soil moisture variability: I. Theoretical basis, Water Resour. Res., 39, 1274, doi:10.1029/2002WR001616, 2003.

Anderson, M. G. and Burt, T. P.: Automatic monitoring of soil moisture conditions in a hillslope spur and hollow, J. Hydrol., 33, 27-36, 1977.
Anderson, S. P., Dietrich, W. E., Montgomery, D. R., Torres, R., Conrad, M. E., and Loague, K.: Subsurface flow paths in a steep unchanneled catchment, Water Resour. Res., 33, 26372653, 1997.

Barling, R. D., Moore, I. D., and Grayson, R. B.: A quasi-dynamic wetness index for characterizing the spatial distribution of zones of surface saturation and soil water content, Water Resour. Res., 30, 1029-1044, 1994.

Beven, K. J. and Kirkby, M. J.: A physically based, variable contributing area model of basin hydrology, Hydrol. Sci. B., 24, 4369, 1979.

Brocca, L., Morbidelli, R., Melone, F., and Moramarco, T.: Soil moisture variability in experimental areas of central Italy, J. Hydrol., 333, 356-373, 2007.

Brohan, P., Kennedy, J. J., Harris, I., Tett, S. F. B., and Jones, P. D.: Uncertainty estimates in regional and global observed temperature changes: A new data set from 1850, J. Geophys. Res.Atmos., 111, D12106, doi:10.1029/2005JD006548, 2006.

Burt, T. P. and Butcher, D. P.: Topographic controls of soil moisture distributions, J. Soil Sci., 36, 469-486, 1985.

Cayan, D. R., Kammerdiener, S. A., Dettinger, M. D., Caprio, J. M., and Peterson, D. H.: Changes in the onset of spring in the western United States, B. Am. Meteorol. Soc., 83, 399-415, 2000.

Daubenmire, R.: A canopy-coverage method of vegetation analysis, Northwest Sci., 33, 43-64, 1959.

Famiglietti, J. S., Rudnicki, J. W., and Rodell, M.: Variability in surface moisture content along a hillslope transect: Rattlesnake Hill, Texas, J. Hydrol., 210, 259-281, 1998.

Famiglietti, J. S., Dongryeol, R., Berg, A. A., Rodell, M., and Jackson, T. J.: Field observations of soil moisture variability across scales, Water Resour. Res., 44, WO1423, doi:10.1029/2006WR005804, 2008.

Famiglietti, J. S., Devereaux, J. A., Laymon, C. A., Tsegaye, T., Houser, P. R., Jackson, T. J., Graham, S. T., Rodell, M., and Van Oevelen, P. J.: Ground-based investigation of soil moisture variability within remote sensing footprints during the Southern Great Plains 1997 (SGP97) Hydrology Experiment, Water Resour. Res., 35, 1839-1851, 1999.

Gómez-Plaza, A., Martínez-Mena, M., Albaladejo, J., and Castillo, V. M.: Factors regulating spatial distribution of soil water content in small semiarid catchments, J. Hydrol., 253, 211-226, 2001.

Grant, L., Seyfried, M., and McNamara, J.: Spatial variation and temporal stability of soil water in a snow-dominated, mountain catchment, Hydrol. Process., 18, 3493-3511, 2004.

Grayson, R. B. and Western, A. W.: Towards areal estimation of soil water content from point measurements: time and space stability of mean response, J. Hydrol., 207, 68-82, 1998.

Grayson, R. B., Western, A. W., Chiew, F. H. S., and Blöschl, G.: Preferred states in spatial soil moisture patterns: local and nonlocal controls, Water Resour. Res., 33, 2897-2908, 1997.

Harkness, A.: Soil survey of Boise Front Project, Idaho. Interim and supplemental report, US Department of Agriculture in cooperation with Boise City and Ada County, Boise, ID, 1977.

Hawley, M. E., Jackson, T. J., and McCuen, R. H.: Surface soil moisture variation of small agricultural watersheds, J. Hydrol., 62, 179-200, 1983.

Hupert, F. and Vanclooster, M.: Intraseasonal dynamics of soil moisture variability within a small agricultural maize cropped field, J. Hydrol., 261, 86-101, 2002. 
IPCC: Climate Change 2007: Impacts, Adaption, and Vulnerability. Intergovernmental Panel on Climate Change, Bussels, 2007.

Jones, S. B., Wraith, J. M., and Or, D.: Time domain reflectometry (TDR) measurement principles and applications, Hydrol. Process., 16, 141-153, 2002.

Jones, P. D., New, M., Parker, D. E., Martin, S., and Rigor, I. G.: Surface air temperature and its changes over the past 150 years, Rev. Geophys. 37, 173-199, 1999.

Kim, G. and Barros, A. P.: Space-time characterization of soil moisture from passive microwave remotely sensed imager and ancillary data, Remote Sens. Environ., 81, 393-403, 2002.

Ledieu, J., de Ridder, P., de Clerck, P., and Dautrebande, S.: A method of measuring soil moisture by time-domain reflectometry, J. Hydrol., 88, 319-328, 1986.

Litaor, M. I., Williams, M., and Seastedt, T. R.: Topographic controls on snow distribution, soil moisture, and species diversity of herbaceous alpine plant vegetation, Niwot Ridge, Colorado, J. Geophys. Res., 113, G02008, doi:10.1029/2007JG000419, 2008.

McNamara, J. P., Chandler, D., Seyfried, M., and Achet, S.: Soil moisture states, lateral flow, and streamflow generation in a semiarid, snowmelt-driven catchment, Hydrol. Process., 19, 40234038, 2005.

Moore, I. D., Burch, G. J., and Mackenzie, D. H.: Topographic effects on the distribution of surface soil water and the location of ephemeral gullies, T. ASAE, 31, 1098-1107, 1988.

Mote, P. W.: Trends in temperature and precipitation in the Pacific Northwest during the twentieth century, Northwest Sci., 77, 271282, 2003.

Oldak, A., Jackson, T. J., and Pachepsky, Y.: Using GIS in passive microwave soil moisture mapping and geostatistical analysis, Int. J. Geogr. Inf. Sci., 16(7), 681-698, 2002.

O'Loughlin, E. M.: Saturation regions in catchments and their relations to soil and topographic properties, J. Hydrol., 53, 229-246, 1981.

Reynolds, S. G.: The gravimetric method of soil moisture determination, Part III, An examination of factors influencing soil moisture variability, J. Hydrol., 11, 288-300, 1970.

Ridolfi, L., D’Odorico, P., Porporato, A., and Rodriquez-Iturbe, I.: Stochastic soil moisture dynamics along a hillslope, J. Hydrol., 272, 264-275, 2003.
Seyfried, M.: Spatial variability constraints to modeling soil water at different scales, Geoderma, 85, 231-254, 1998.

Seyfried, M. S., Grant, L. E., Marks, D., Winstral, A., and McNamara, J.: Simulated soil water storage effects on streamflow generation in a mountainous snowmelt environment, Idaho, USA, Hydrol. Process., 23, 858-873, 2009.

Stewart, I. T., Cayan D. R., and Dettinger M. D.: Changes toward earlier streamflow timing across western North America, J. Climate, 18, 1136-1155, 2005.

Tarboton, D. G.: Terrain analysis using digital elevation models in hydrology, 23rd ESRI international users conference, San Diego, California, 7-11 July, 2003.

Teuling, A. J. and Troch, P. A.: Improved understanding of soil moisture variability dynamics, Geophys. Res. Lett., 32, L05404, doi:10.1029/2004GL021935, 2005.

Tromp-van Meerveld, H. J., and McDonnell, J. J.: On the interrelations between topography, soil depth, soil moisture, transpiration rates and species distribution at the hillslope scale, Adv. Water Res., 29, 293-310, 2006.

Vachaud, G., Passerat De Silans, A., Balabanis, P., and Vauclin, M.: Temporal stability of spatially measured soil water probability density function, Soil Sci. Soc. Am. J., 49, 822-828, 1985.

Western, A. W. and Grayson, R. B.: The Tarrawarra data set: Soil moisture patterns, soil characteristics, and hydrological flux measurements, Water Resour. Res., 10, 2765-2768, 1998.

Western, A. W., Grayson, R. B., Blöschl, G., Willgoose, G. R., and McMahon, T. A.: Observed spatial organisation of soil moisture and its relation to terrain indices, Water Resour. Res., 35, 797810, 1999.

Western, A. W., Zhou, S., Grayson, R. B., McMahon, T. A., Blöschl, G., and Wilson, D. J.: Spatial correlation of soil moisture in small catchments and its relationship to dominant spatial hydrological processes, J. Hydrol., 286, 113-134, 2004.

Williams, C. J.: Characterization of the spatial and temporal controls on soil moisture and streamflow generation in a semiarid headwater catchment, unpublished M.S. Thesis, Boise State Univ., Boise, 2005.

Wood, J. D.: The geomorphological characterization of digital elevation models, unpublished Ph.D. Thesis, Univ. of Leicester, Leicester, 1996. 